\title{
Single dose antibiotic prophylaxis in planned surgical procedures in Gwalior
}

\author{
Dutt CK ${ }^{1}$, Shukla $\mathbf{A}^{2}$, Dutt RD ${ }^{3}$
}

${ }^{1}$ Dr. Mrs Chandrakala Dutt, Assistant Professor, Department of Surgery, ${ }^{2}$ Dr. Mrs. Abha Shukla, Assistant Professor, Department of Ophthalmology. Both are affiliated to J.A. Groups of Hospital \& G.R. Medical College, Gwalior, MP, India, ${ }^{3}$ Dr. R.D. Dutt, MD (Pediatrics), PGDDN (Neurology), Associate Professor, Department of Pediatrics, Bundelkhand Medical College, Sagar, MP, India.

Address for Correspondence: Dr. R.D. Dutt, 112- Tansen Nagar. Gwalior, M.P., Email - dr rddutt@ rediffmail.com

\begin{abstract}
Introduction: The aim of present study was to prevent the development of the surgical wound infection. Design: Prospective study. Methodology: Study was conducted in surgical ward of J.A. Group of Hospitals, Gwalior, MP, India from May 2014 to April 2015. Study was consisting a total of 125 patients admitted in surgical ward. Statistically - SSPS - 10 systems was applied for study. Results: A total of 125 patients were studied under five group depending on the antibiotics. A, B, C, D groups were given only a single dose of antibiotics while group E was given full course of antibiotics during preoperative, intraoperative and postoperatively. Out of 125 cases, only 5 patients had clinical and bacteriological evidenced of wound sepsis in different groups of single dose antibiotics and one case in group E of multiple doses of antibiotic given. Wound infection rate in clean was $20 \%$ in ceftazidine, $12.5 \%$ with piperacillin tazobactum and cefoperazone sulbactum and $21.1 \%$ in multiple doses group. No infection was reported with amoxycillin - clavulanic acid. Staphylococcus, E. coli and klebsiella were offending agents \& anaerobic infections were not found. Conclusion: Single dose of antibiotic prevents the suppression of normal sensitive microbial flora, which is usually seen with multiple doses of antibiotics use. In this way, it helps in keeping the patients infection free without interfering with the naturally inherited immunological status of the patient.
\end{abstract}

Keyword: Staphylococcus, Amoxicillin Clavulanic Acid, Antibiotic prophylaxis, planned surgical procedure

\section{Introduction}

Many serious and time consuming operations performed with great skill and labour get spoiled in a minute by a tiny microbe - most common being the staphylococcus. The various neurosurgical, cardiothoracic and plastic surgeries, whose expertise has already sucked nearly half of a surgeon's carrier, are casted into tears of pus in the wound by these selfish microbes. How depressing it is to look at the patient feeling ill and lethargic even seven days after operation, making him/her weaker day by day, both by lowering his/her resistance to microbes and to a weeping pocket caused due to prolonged use of prophylactic antibiotics.

Postoperative wound infection may results from many

\footnotetext{
Manuscript received: $14^{\text {th }}$ Aug 2015

Reviewed: $30^{\text {th }}$ Aug 2015

Author Corrected: $17^{\text {th }}$ Sept 2015

Accepted for Publication: $28^{\text {th }}$ Sept 2015
}

causes out of which 'microbial contamination' is the factor which is influenced by antibiotic administration.

Since the concept of antimicrobial prophylaxis has emerged, several workers searched for optimal antimicrobial drug, it's route and timing of administration, with ultimate goal to achieve zerosepsis.

In the very early phase the antibiotics were only administered post operatively for treatment of already established surgical wound infection. Later on the concept of antibiotic prophylaxis was introduced. Initially the antibiotics were administered post-operatively for a prolonged period but without any significant reduction in the surgical wound infection rates. It was subsequently discovered that antibiotics need to administer preoperatively for prophylaxis of 
wound infection. The use of preoperative systemic antibiotics has brought down the incidence of wound infection considerably.

By giving a single dose of antibiotic immediately before operation and keeping its blood level arised only until the patient is back in bed and conscious, the well known disadvantages of prolonged antibiotic prophylaxis could be avoided, since there would not be any time to suppress the normal bacteria.

\section{Aims and Objectives}

- To assess the efficacy of single dose antibiotic in comparison with multiple doses of antibiotics given as antimicrobial prophylaxis in prevention of post operative wound infection.

- To identify which drug is the best option for single dose antibiotic prophylaxis to prevent postoperative wound infection.

- To prevent the suppression of normal sensitive microbial flora seen with multiple doses of antibiotics.

- To reduce the expenditure of the patient due to prolonged antibiotic use without affecting the final results of operation.

\section{Material and Methods}

The present prospective study consisting of a total of 125 patients admitted in surgical wards of J.A. Group of Hospitals, Gwalior between May 2014 to April 2015. All patients underwent elective surgeries which lasted for less than 3 hours.

\section{Inclusion Criteria}

- Patients of all sex and age were included in the study.

\section{Exclusion Criteria}

- Patients with history to allergy to any of the antibiotics were excluded from study, Patients with infections at other sites were excluded.

- Patients who had received antibiotics within previous 7 days before operation were excluded from the study except group E.

- Patients who had existing indication for antibiotic prophylaxis (i.e. valvular heart disease) and known renal or liver impairment (potentially immunocompromised) patients were excluded from study.

- All patients were investigated for anemia, tuberculosis, diabetes mellitus, cardivascular disease and high serum creatinine more than $2 \mathrm{mg} / \mathrm{dl}$ were excluded from the study.
- All patients were given antibiotics intravenously at the time of induction of anaesthesia except group E in which full course of preoperative, intraoperative and postoperative antibiotic was given.

- Patients were randomized into five groups according to the antibiotics.

\section{Group A: $\quad$ Ceftazidime \\ Group B : $\quad$ Piperacilline Tazobactum \\ Group C: Amoxycillin \& Clavulanic \\ Acid

$\begin{array}{ll}\text { Group D: } & \text { Cefoparazone Sulbactum } \\ \text { Group E: } & \text { Full Course of Antibiotic }\end{array}$ \\ Antibiotic Selection \\ Following points were kept in mind while choosing these drugs - \\ 1. Broad-spectrum antibiotic agent that covers the spectrum of micro-organisms usually involved in the specific type of operation. \\ 2. Fewer side effects. \\ 3. Easy availability. \\ 4. Costeffectiveness.}

Ceftazidime: Ceftazidime is bectericidal third generation cephalosporin antibiotic which is resistant to most betalactamases and active against wide range of gram negative and gram positive bacteria.

Piperacillin Tazobactum: It is an injectable antibacterial combination product consisting of semisynthetic penicillin antibiotic piperacillin and the betalactmase inhibitor tazobactum for intravenous administration.

Cefoparazone- Sulbactum: Cefoparazone is third generation cefolosporin which act against sensitive organisms during the stage of active multiplication by inhibiting biosynthesis of cell wall mucopeptide.

\section{Pre-Operative Methods:}

1. Shaving was done 24 hours prior to surgery.

2. Patient was shifted to the operation theatre after applying a sterile bandage over the proposed part of surgery. Patients were given clean gowns to wear and then enter inside the operation theatre.

3. In the operation threatre, skin preparation was done by Savlon scrub followed by Povidone Iodine and Spirit.

Intra-Operative Methods: Single dose of planned antibiotic was administered intravenously at the time of induction of anaesthsia. 


\section{Post-Operative Follow Up}

1. Wound was examined after taking aseptic precaution. This was done on second, third, fourth \& sixth day of operation.
2. After seventh postoperative day, stitches were removed and patient was discharged. Patient was followed again in second week in Out Patient Department.

\section{Observations}

In the present study, a total of 125 cases who underwent planned surgery, in surgical wards of J.A. Group of Hospitals and G.R. Medical College, Gwalior (M.P.) between May 2014 to April 2015were included.

This study was carried out in five groups -

Group A- Patients who received Ceftazidime

Group B - $\quad$ Patients who received Pipracilline Tazobactum

Group C- $\quad$ Patients who received Amoxicillin \& Clavulanic acid.

Group D- $\quad$ Patients who received Cefoparazone Sulbactum

Group E - $\quad$ Patients who received full course of antibiotics

- Each group comprised of 25 patients.

- Each antibiotic was administered at the time of induction of anesthesia.

- Only planned surgical procedures were included in this study.

- In all five groups, postoperative evaluation of the wound was done \& any discharge from the wound was sent for bacteriological culture and sensitivity testing.

Table No. 1: Age distribution of cases

\begin{tabular}{|c|c|c|c|c|c|c|c|c|c|c|}
\hline \multirow{2}{*}{$\begin{array}{l}\text { Age of } \\
\text { pt. (yrs) }\end{array}$} & \multicolumn{2}{|c|}{ Group A } & \multicolumn{2}{|c|}{ Group B } & \multicolumn{2}{|c|}{ Group C } & \multicolumn{2}{|c|}{ Group D } & \multicolumn{2}{|c|}{ Group E } \\
\hline & $\begin{array}{l}\text { No.of } \\
\text { pt. } \\
(n=25)\end{array}$ & \begin{tabular}{|l} 
Pt. \\
infec \\
ted
\end{tabular} & $\begin{array}{l}\text { No.of } \\
\text { pt. } \\
(n=25)\end{array}$ & $\begin{array}{l}\text { Pt. } \\
\text { infected }\end{array}$ & $\begin{array}{l}\text { No.of } \\
\text { pt. } \\
(n=25)\end{array}$ & $\begin{array}{l}\text { Pt. } \\
\text { infecte } \\
\text { d }\end{array}$ & $\begin{array}{l}\text { No.of } \\
\text { pt. } \\
(n=25)\end{array}$ & $\begin{array}{l}\text { Pt. } \\
\text { infecte } \\
\text { d }\end{array}$ & $\begin{array}{l}\text { No.of } \\
\text { pt. } \\
(n=25)\end{array}$ & $\begin{array}{l}\text { Pt. } \\
\text { infecte } \\
\text { d }\end{array}$ \\
\hline$<1$ & 1 & - & 0 & - & 0 & - & 0 & - & 0 & - \\
\hline $1-10$ & 1 & - & 1 & - & 2 & - & 0 & - & 1 & - \\
\hline $11-20$ & 5 & - & 4 & - & 3 & - & 1 & - & 3 & - \\
\hline $21-30$ & 7 & - & 6 & - & 5 & - & 7 & - & 6 & - \\
\hline $31-40$ & 3 & - & 6 & - & 4 & - & 10 & 1 & 2 & - \\
\hline $41-50$ & 1 & - & 3 & 1 & 5 & - & 1 & - & 3 & - \\
\hline $51-60$ & 4 & 1 & 3 & - & 1 & - & 4 & - & 4 & - \\
\hline $61-70$ & 3 & 1 & 2 & - & 4 & - & 2 & 1 & 4 & 1 \\
\hline $71-80$ & 0 & - & 0 & - & 1 & - & 0 & - & 2 & - \\
\hline
\end{tabular}

Above table shows that no infection was reported in age group. When chi-square test applied for rate of infection in 6170 age group for all five groups chi-square test value is 3.01 and $\mathrm{p}=0.55$ (difference is significant when $\mathrm{p}=<0.05$ ) it shows that no significant difference in rate of infection in all groups and they are comparable.

Table No. 2: Sex distribution of cases

\begin{tabular}{|l|l|l|l|l|}
\hline \multirow{2}{*}{ Group } & \multicolumn{2}{|l|}{} & Females \\
\cline { 2 - 5 } & Total no. of patient & No. patient Infected & Total & No. patient Infected \\
\hline A $(n=25)$ & 15 & 1 & 10 & 1 \\
\hline B $(n=25)$ & 15 & 0 & 10 & 1 \\
\hline C $(n=25)$ & 15 & 0 & 10 & 0 \\
\hline$D(n=25)$ & 15 & 1 & 10 & 1 \\
\hline E $(n=25)$ & 15 & 0 & 10 & 1 \\
\hline
\end{tabular}


4 females and 2 males were infected in different goups.

Table No. 3 (a): Operative time and incidence of wound Infection

\begin{tabular}{|c|c|c|c|c|c|c|c|c|c|c|}
\hline \multirow{2}{*}{$\begin{array}{l}\text { Duration } \\
\text { (mins) }\end{array}$} & \multicolumn{2}{|c|}{ Group A } & \multicolumn{2}{|c|}{ Group B } & \multicolumn{2}{|c|}{ Group C } & \multicolumn{2}{|c|}{ Group D } & \multicolumn{2}{|c|}{ Group E } \\
\hline & $\begin{array}{l}\text { Total } \\
\text { No. of } \\
\text { pt. }\end{array}$ & $\begin{array}{l}\text { Patients } \\
\text { Infected }\end{array}$ & $\begin{array}{l}\text { Total } \\
\text { No. of } \\
\text { pt. }\end{array}$ & $\begin{array}{l}\text { Pt. } \\
\text { Infected }\end{array}$ & $\begin{array}{l}\text { Total } \\
\text { No. of } \\
\text { pt. }\end{array}$ & $\begin{array}{l}\text { Pt. } \\
\text { Infe } \\
\text { cted }\end{array}$ & $\begin{array}{l}\text { Total } \\
\text { No. of } \\
\text { pt. }\end{array}$ & $\begin{array}{l}\text { Pt. } \\
\text { Infecte } \\
\text { d }\end{array}$ & $\begin{array}{l}\text { Total } \\
\text { No. of } \\
\text { pt. }\end{array}$ & $\begin{array}{l}\text { Pt . } \\
\text { Infected }\end{array}$ \\
\hline $0-30$ & 5 & 0 & 7 & 0 & 3 & 0 & 5 & 0 & 3 & 0 \\
\hline $31-60$ & 10 & 0 & 9 & 0 & 15 & 0 & 9 & 0 & 7 & 0 \\
\hline $61-90$ & 4 & 0 & 5 & 0 & 5 & 0 & 10 & 2 & 10 & 0 \\
\hline $91-120$ & 4 & 1 & 4 & 1 & 2 & 0 & 0 & 0 & 4 & 1 \\
\hline$>120$ & 2 & 1 & 0 & 0 & 0 & 0 & 1 & 0 & 1 & 0 \\
\hline
\end{tabular}

At the completion of each operative procedure, the time of the operation in minutes was recorded.

Above table shows that maximum infection rate is seen in group A when operative time was $>120$ minutes followed by equal 4 cases in group A, B \& E when operative time was 91 to 120 minutes and minimum 2 cases in group C when operative time was 61 to 90 minutes while no infection is seen in any of group when operative time was less than 60 minutes. As the duration of operation increased, a progressive rise in the infection rate was observed. It was also found that majority of severe infections were associated with prolonged surgery.

Table No. 3 (b): Operative time and incidence of wound infection

\begin{tabular}{|l|l|l|l|l|l|l|l|l|l|l|}
\hline \multirow{2}{*}{$\begin{array}{l}\text { Duration } \\
(\text { mins) }\end{array}$} & \multicolumn{2}{|l|}{ Group A } & \multicolumn{2}{l|}{ Group B } & \multicolumn{2}{l|}{ Group C } & \multicolumn{2}{l|}{ Group D } & \multicolumn{2}{l|}{ Group E } \\
\cline { 2 - 11 } & $\begin{array}{l}\text { Total } \\
\text { No. of } \\
\text { pt. }\end{array}$ & $\begin{array}{l}\text { Pt . } \\
\text { Infected }\end{array}$ & $\begin{array}{l}\text { No. of } \\
\text { pt. }\end{array}$ & $\begin{array}{l}\text { Pt . } \\
\text { Infected }\end{array}$ & $\begin{array}{l}\text { Total } \\
\text { No. of } \\
\text { pt. }\end{array}$ & $\begin{array}{l}\text { Pt . } \\
\text { Infe } \\
\text { cted }\end{array}$ & $\begin{array}{l}\text { Total } \\
\text { No. of } \\
\text { pt. }\end{array}$ & $\begin{array}{l}\text { Pt . } \\
\text { Infecte } \\
\text { d }\end{array}$ & $\begin{array}{l}\text { Total } \\
\text { No. of } \\
\text { pt. }\end{array}$ & $\begin{array}{l}\text { Pt . } \\
\text { Infecte } \\
\text { d }\end{array}$ \\
\hline $0-60$ & 15 & 0 & 16 & 0 & 18 & 0 & 14 & 0 & 10 & 0 \\
\hline $61-120$ & 8 & 1 & 9 & 1 & 7 & 0 & 10 & 2 & 14 & 1 \\
\hline$>120$ & 2 & 1 & 0 & 0 & 0 & 0 & 1 & 0 & 1 & 0 \\
\hline
\end{tabular}

Above table shows no infection was reported when operative time less then 60 minutes the rate of infection among the operative duration between 61-120 minutes were following 1 cases in group A, 1 cases in group B , 2 cases in group D, 1 cases in group $\mathrm{E}$ and no wound infection reported in group $\mathrm{C}$ when chi-square test applied $\mathrm{p}=0.73$ that mean no significant difference was there in any of group either single or multiple doses of antibiotic used. The rate infection increased with the operative time proven with wound infection rate in group A $(50 \%)$ when operative time was $>120$ minutes.

Table No. 4: Overall wound infection rate

\begin{tabular}{|l|l|l|l|}
\hline Group & Total No. of patients & Pt. infected & $\%$ \\
\hline A & 25 & 2 & 8 \\
\hline B & 25 & 1 & 4 \\
\hline C & 25 & - & - \\
\hline D & 25 & 2 & 8 \\
\hline E & 25 & 1 & 4 \\
\hline
\end{tabular}

This study shows that overall wound infection rate is maximum in group A\&D 4 cases followed by group B \& E 2 cases and no wound infection seen in group $\mathrm{C}$. When chi-square test applied all groups was comparable no significant difference was observed $(\chi 2=2.45, \mathrm{p}=0.6)$. 


\section{Discussion}

The purpose of the present study was to examine the influences of a single antimicrobial agent on the incidence of wound sepsis on patients undergoing elective surgical procedures. Whether a single dose of prophylactic antibiotic is good enough to take care and at the same time patient does not shows any local or systemic signs of infection. In this way, it is obvious that the total expenditure borne by the hospital or the patient can also be significantly lowered by reducing the antibiotic load.

A wide range of different age group patients was studied in this trial. Wound infection rate increased steadily in patients older than 30 years. Similar findings were observed by the public health laboratory service in 1995, the committee on Trauma in 1999[1]. In the present study, post operative wound infection rate was seen more in elderly patients like in 61-70 years age in both study groups. The higher rate of infection among the older patients may be due to poor health and general debility, carrier state of multi resistant micro organism, and reduced immunological efficiency extremes of age as described by Dineen in 2004. Patients more than 66 years of age are six times more likely to develop infection than are patients 1-14 years of age. In a study of 468 clean wounds and found an infection rate of $3.4 \%$ in patients $<65$ years and $2.7 \%$ in $>65$ years. Even in clean contaminated procedures age has been associated with an increased infection rate as reported by Cleason in a relatively homogenous population of patients undergoing elective colorectal procedures [2].

Out of 125 cases, 75 cases were males and rest was females. The overall infection rate in females in the present study was much higher than that of males but there were equal incidence $(10 \%)$ of wound infection in females of groups in which single antibiotic was given to group in which full course of antibiotics was given and it shows that there is not much difference in wound infection rates when single antibiotic given in place of multiple doses in respective of the sex.

An association was observed between the infection rate and the duration of operation. The incidence of postoperative wound infection increased with increase in duration of operation. Similar results were reported by Prakash. According to these studies infection rate percentage in less than 60 minutes are $6.3 \%$ and $0.9 \%$ respectively and in the present study it is $0 \%$ in all five groups while in 61-120 minutes the infection rates are
$13.7 \%$ and $4.2 \%$ respectively and in the present study it is between 7.1 to $20 \%$ in different groups but in greater than 120 minutes the infection rates are $40.7 \%$ and $50.6 \%$ respectively and in the present study it is $50 \%$.in group A.

The rate of infection of clean wound increases significantly with increase in duration of operation in both groups either single or multiple dose antibiotics without any significant difference in infection rates in all groups $(\mathrm{p}=.83)$. The rate of infection of clean wounds roughly doubles with every hour (Cruse et al. 1980). The association between the two may be the result of increased bacterial contamination with time, increased damage of wound cell due to long exposure, increased exposure to the theatre atmosphere and the increased amount of suture and electrocoagulation reducing the local resistance of the wound. To this may be added the increased manipulation and systemic insult to the patient through blood loss 2001[3].

The infection rates in clean wounds as reported by Cruse et al in different studies conducted were $1.8 \%$ and 5\% respectively. In present study $5.1 \%$ infection rate reported in group $\mathrm{D}$ no infection was there in other groups.

The declining incidence of post operative wound infection rate in Indian settings particularly in the last decade is probably due to increased awareness of aseptic and antiseptic precautions, the dreaded diseases like AIDS and Hepatitis B have made every surgeon to be over cautions starting right from entering in to the operation theatre and then finally leaving the theatre after operation. It is needless to stress that this encompasses the washing of hands, wearing of sterile gown and gloves which all forms the important keys in keeping the patients infection free. The newer techniques of article sterilization (Autoclaving, Gamma radiation etc.), improved theatre care, and cleanliness have all led to increase in the operation theatre standard in the past few years.

The postoperative wound infection rate in clean surgeries in the present study is between $11.1 \%$ to $20 \%$ in different groups with no wound infection reported in group $\mathrm{C}(\mathrm{p}=0.7)$.

Shaving done immediately before operation prevents bacterial growth in the razor nick. This study shows that shaving done 24 hours prior to operation significantly increases the risk of postoperative wound infection as 
compared to shaving done just one hour prior to operation but there are no significant difference was observed in infection rate when single dose antibiotic given or multiple doses of antibiotic given and shaving done before $24 \mathrm{hrs}$ of surgery $(\mathrm{p}=0.9$ ) or shaving done $1 \mathrm{hr}$ prior to surgery $(\mathrm{p}=0.5)$. The explanation for this is that when shaving is done 24 hours prior to operation, there is increase in the proliferation of micro organisms at the site of razor nicks which further lead to operative wound contamination resulting in wound sepsis.

The prophylaxis of primary wound sepsis depends principally on taking measures to minimize exogenous and endogenous wound contamination and the use of potent antibiotic parenterally. The avoidance of secondary sepsis is a different matter related to hospital cross infection 1997[4].

Griffith in 2006 [5] reported frequent infection by coliform infection following preoperative single intravenous use of Tobramycin and Lincomycin reported dominance of Staphylococci in clean wounds and intestinal organism in contaminated wounds 2006 [6] and reports of public health laboratory service in 1960 quote very high figure of Staphylococci isolation i.e. $50 \%$ and $45 \%$ respectively. in 1996 [7] oagulase positive staphylococci was reported in $35 \%$ of wounds. in 2001[8] reported 29\% of incidence of Staphylococci wound infection. in 1999 [9] of Staphylococci and Coliform micro organisms. In the present study Staphylococcus aureus was the commonest organism isolated from the cultures of infected post operative wounds than E. coli was isolated from wound cultures of the patients. Anaerobic organism were not isolated from any of the postoperative infected wounds in the present study.

The chief place of infection of surgical wounds due to Staphylococci is the operation theatre as shown by studies of many workers. The Surgeons, Nurses, OT boys and students may be the nasal carriers. It has been reported by many workers that there is now a shift in the pattern of hospital acquired infections from Staphylococci to Gram negative organism in 1998 [10], showed increased isolation of Gram negative organisms from the wounds where operations were performed on Gastrointestinal tract. Similar results were all reported in 2004 [11]. The results are comparable to various studies that have indicated a relationship between nasal carriage of S. aureus and subsequent post operative infection. Reported Staphylococcus from skin is the major pathogen responsible for post operative infection.
Patients own skin flora as major source of wound infection.

The current study did not demonstrate a difference in the rate of infection between patients receiving preoperative antibiotics alone (5\%) versus those receiving preoperative followed by postoperative multiple doses antibiotics $(4 \%, p=0.8)$. The $\mathrm{p}$ value of 0.8 confirms the validity of this study. The findings in this study coincide well with the experimental animal studies and other clinical studies regarding the use of prophylactic antibiotics Overall, 6 (4.8\%) patients developed infectious complications, five from the antibiotic prophylaxis group in which single antibiotic was given and 1 from the group $\mathrm{E}(\mathrm{p}=0.6)$ in which multiple doses of antibiotic given. All these patients were treated conservatively, i.e. antibiotic treatment in all cases plus wound opening and delayed primary closure in 1 case.

\section{Conclusion}

- $\quad$ Only a single dose of antibiotic administered at the time of induction of anesthesia is able to prevent post operative wound infection as efficiently as multiple doses of antibiotic prophylaxis.

- Higher drug concentration achieved at the time of wound closure, in this manner is perhaps the best option for administering prophylactic antibiotics.

- Single dose of antibiotic prevents the suppression of normal sensitive microbial flora, which is usually seen with multiple doses of antibiotics use. In this way, it helps in keeping the patients infection free without interfering with the naturally inherited immunological status of the patient.

- Amoxicillin Clavulanic acid is perhaps the best option in preventing post operative wound infection among the single dose antibiotics.

- Single dose of antibiotic administered prophylactically did not lead to any sign of systemic infection which is usually the case as an insult due to immunological suppression following prolonged use of antibiotic.

- Single dose of antibiotic as antimicrobial prophylaxis in planned surgical procedures also reduces the patient's as well as the hospital's expenditure significantly.

Funding: Nil

Conflict of interest: None.

Permission of IRB: Yes 


\section{References}

1. Prakash A. Postoperative wound infection Ind. J. Surg : Feb.: 1973;57:64.

2. Cruse A. five year prospective study of 23, 649 surgical wounds. arch. Surg. 1996;107-206. Cruse PJ, Foord R. A five-year prospective study of 23,649 surgical wounds. Arch Surg. 1973 Aug;107(2):206-10.

3. Miles A.A. The enhancement of infection during shock produced by bacterial toxins and other agents., Br. J. Exp. Pathol. 2001;37-73. MILES AA, NIVEN JS. The enhancement of infection during shock produced by bacterial toxins and other agents. Br J Exp Pathol. 1950 Feb;31(1):73-95.

4. Pollock A.V., Leaper D.J. and Evans M: Single dose intraincisional propbhylaxis with cephaloridine and ampicillin. Br. J. Surg. 1997;322-325. Pollock AV, Leaper DJ, Evans M. Single dose intra-incisional antibiotic prophylaxis of surgical wound sepsis: a controlled trial of cephaloridine and ampicillin. $\mathrm{Br} \mathrm{J}$ Surg. 1977 May;64(5):322-5.

5. Griffiths D.A. Single dose preoperative antibiotic prophylaxis in gastrointestinal surgery. Thelancet: Aug. 14: 2006;325-328. Griffiths DA, Simpson RA, Shorey
BA, Speller DC, Williams NB. Single-dose peroperative antibiotic prophylaxis in gastrointestinal surgery. Lancet. 1976 Aug 14;2(7981):325-8.

6. Sundararaman S. Bacteriology of wound sepsis and a study of postoperative wound infection. in Indian $\mathbf{J}$. Surg. : 2007;39:126-133.

7. Bhargava K.S. and Singh R.P. Studies on hospital infecstions. Indian Practitioner 1996;1056. Bhargava KS, Atal PR, Singh RP. Studies on hospital infection. Indian Pract. 1966 Oct;19(10):705-9.

8. Sengupta. Bacterial flora of sepsis. Indian J. Surg. 2001;39:126-133.

9. Heeden J.A. Incidence of wound infection in common surgical procedures Surg. Gynaecol. Obstet 1999:557-560. Coles B, van Heerden JA, Keys TF, Haldorson A. Incidence of wound infection for common general surgical procedures. Surg Gynecol Obstet. 1982 Apr;154(4):557-60.

10. Barber M. Hospital infections yesterday and today. J Clin Pathol. 1961 Jan;14:2-10.

11. Dineen P: Major infection in postoperative period Surg. Clin. of N. America 2004:853(44).

\section{How to cite this article?}

Dutt CK, Shukla A, Dutt RD. Single dose antibiotic prophylaxis in planned surgical procedures in Gwalior. Int J Med Res Rev 2015;3(8):877-883. doi: 10.17511/ijmrr.2015.18.165. 